\title{
Política cambial no Brasil: um esquema analítico*
}

\author{
Exchange rate policy in Brazil: An analytical framework
}

PEDRO ROSSI**

RESUMO: Esse artigo trata da política cambial no Brasil a partir de um enfoque centrado na institucionalidade do mercado de câmbio brasileiro. O objetivo é avaliar como essa institucionalidade condiciona as políticas de câmbio no Brasil e, em particular, como a especulação opera nessa institucionalidade. Defende-se a ideia de que o mercado de câmbio brasileiro é particularmente permeável à especulação financeira e, por isso, uma política cambial mais adequada ao desenvolvimento econômico depende da regulação do mercado de câmbio e, em particular, do mercado de derivativos.

PALAVRAS CHAVE: câmbio; política cambial; derivativos; controles de capital.

ABSTRACT: This paper aims to address the exchange rate policy in Brazil from an approach centered in the Brazilian foreign exchange market's institutional framework. The purpose is to evaluate how this institutionality affects the exchange rate policies and, in particular, how financial speculation operates in this institutional framework. It argues that the Brazilian foreign exchange market is particularly susceptible to financial speculation and therefore the regulation of foreign exchange market and, in particular, the derivatives market, is recommended to allow a more appropriate exchange rate policy for economic development. KEYWORDS: exchange rate; exhange rate policy; derivatives; capital controls.

JEL Classification: F310; G130; O240.

\section{INTRODUÇÃO}

Desde 1999, o regime de câmbio flutuante brasileiro testemunhou as mais diversas experiências no plano da flutuação cambial (ciclos longos de apreciação, depreciações abruptas, períodos de estabilidade e também de volatilidade intensa)

\footnotetext{
* Artigo originalmente preparado para o $10^{\circ}$ Fórum de Economia FGV-EESP.

* Professor e doutor do Instituto de Economia da Universidade Estadual de Campinas - Unicamp. Pesquisador do Centro de Estudos de Conjuntura e Política Economica (CECON/Unicamp). E-mail: pedrolrossi@gmail.com; Submetido: 13abril/2013; Aprovado: 9/outubro/2014.
} 
e igualmente no plano das políticas cambiais (intervenções, swaps, controle sobre diversos fluxos de capital, regulação no mercado interbancário, taxação de derivativos). A despeito dessa experiência a questão da política cambial no Brasil ainda aparece como uma questão mal resolvida, tanto no que se refere à administração da volatilidade, quanto à administração do patamar da taxa de câmbio.

Nesse contexto, esse artigo busca contribuir para a discussão da política cambial no Brasil a partir de um enfoque centrado na institucionalidade do mercado de câmbio brasileiro. O objetivo é avaliar como essa institucionalidade condiciona as políticas de câmbio no Brasil (como as intervenções do banco central, os controles sobre fluxos de capital, a regulação sobre a posição dos bancos e a taxação sobre as operações de derivativos) e, em particular, como a especulação opera nessa institucionalidade. Defende-se a ideia de que o mercado de câmbio brasileiro é particularmente permeável à especulação financeira e, por isso, uma política cambial mais adequada ao desenvolvimento econômico, que permita a passagem para outro padrão de flutuação cambial - menos volátil, mais adequado às necessidades do parque produtivo brasileiro - depende da regulação do mercado de câmbio e, em particular, do mercado de derivativos.

$\mathrm{Na}$ primeira seção deste artigo, analisam-se os motivos para uma política cambial ativa classificando-os de acordo com sua natureza, real ou financeira. $\mathrm{Na}$ segunda, procura-se mostrar os indícios de especulação e arbitragem no mercado de câmbio brasileiro a partir de dados das posições abertas no mercado futuro. Já a terceira seção, descreve a institucionalidade do mercado de câmbio brasileiro e, a partir dela, analisa-se o processo de formação da taxa de câmbio e o papel da política cambial. Destaca-se, nessa seção, a descrição do circuito especulação-arbitragem que tem origem no mercado futuro de câmbio. Por fim, última seção apresenta algumas considerações finais.

\section{MOTIVOS PARA UMA POLÍTICA CAMBIAL ATIVA}

A despeito da redundância, vale dizer que a principal virtude do regime de câmbio flutuante é sua flexibilidade. Diante de um contexto internacional como o atual, em que se observa um alto grau de incerteza associado à alta volatilidade de variáveis financeiras e de preços de commodities, a flexibilidade cambial permite a absorção de choques externos que poderiam, de outro modo, ter um forte impacto na economia doméstica. Por exemplo, as mudanças bruscas nos preços relativos, quando não absorvidas rapidamente pela taxa de câmbio, podem gerar pressões inflacionárias e assim sobrecarregar a política monetária. Portanto, diante do atual contexto internacional, a institucionalização de um regime de câmbio com alguma taxa de referência (meta, bandas cambiais ou zona-alvo) pode gerar desequilíbrios macroeconômicos importantes.

Se por um lado algum grau de flexibilidade é bem-vindo, por outro, o excesso de flexibilidade pode levar a distorções de diversas naturezas. O debate sobre o uso ativo da política cambial é extenso, mas em linhas gerais passa pelo reconhecimen- 
to de motivos que fazem com que a taxa de câmbio determinada pelo mercado não seja necessariamente a mais adequada ao processo de desenvolvimento econômico. Para efeito analítico, apresentam-se quatro motivos que justificam uma política cambial ativa (Figura 1). Esses se dividem em dois grupos, aqueles ligados a fatores reais que impactam na conta corrente e àqueles derivados de motivações financeiras, decorrente dos fluxos de capital e do mercado de derivativos.

Figura 1: Quatro motivos para uma política cambial ativa

\begin{tabular}{|l|cc|}
\hline $\begin{array}{l}\text { Motivos } \\
\text { Politica cambial }\end{array}$ & Reais & Financeiros \\
\cline { 2 - 3 } $\begin{array}{l}\text { Administração } \\
\text { da volatilidade }\end{array}$ & $\begin{array}{l}\text { 1. Ciclo de preços } \\
\text { de commodities }\end{array}$ & $\begin{array}{c}\text { 3. Ineficiência dos } \\
\text { mercados financeiros }\end{array}$ \\
\cline { 2 - 3 } $\begin{array}{l}\text { Administração } \\
\text { do patamar }\end{array}$ & 2. Doença holandesa & 4. Carry trade \\
\hline
\end{tabular}

Fonte: Elaborado pelo autor.

Motivo 1. O primeiro motivo para uma política cambial ativa é o ciclo de preços de commodities. Considerando o modelo de Hicks (1974), que diferencia os mercados entre fixprice e flexprice, tem-se que os setores que produzem bens industriais tendem a ajustar as quantidades produzidas perante choques de deman$\mathrm{da}$, enquanto os setores que produzem commodities tendem a ajustar os preços. Isso decorre da estrutura de competição e da natureza do processo produtivo em cada setor. No caso das commodities - bens padronizados, com ciclo de produto geralmente mais longo e dificuldade de trabalhar com capacidade ociosa - torna-se mais difícil responder rapidamente às variações na demanda com mudanças na quantidade ofertada.

Dessa forma, a receita de exportação do país produtor de commodities tende a ser mais volátil que aquela de um país exportador de bens industriais e, portanto, a oferta de divisas decorrente do comércio externo dependerá do ciclo de preços dos produtos básicos. Essa instabilidade é transmitida para a taxa de câmbio e com isso afeta o restante da economia. Portanto, em países com uma pauta de exportação fortemente baseada em commodities, a política cambial é importante para amenizar o impacto da volatilidade desses preços na taxa de câmbio.

Motivo 2. A existência de um setor exportador de commodities e recursos naturais com altas vantagens competitivas leva ao segundo argumento ligado à conta-corrente que justifica o uso de uma política cambial ativa. Conforme Bresser-Pereira (2008), o protagonismo desse setor em uma economia nacional submete-a aos riscos da "doença holandesa", que se manifesta como uma tendência crônica à apreciação cambial. Um dos pontos relevantes dessa abordagem é a identificação de uma taxa de câmbio de equilíbrio para a conta-corrente cujo nível é mais apre- 
ciado do que aquele requerido para o desenvolvimento de um setor industrial competitivo. ${ }^{1}$

Mesmo que o conceito de "taxa de equilíbrio" e o caráter "crônico" da tendência à apreciação sejam objetos de debate, a tese da doença holandesa traz argumentos importantes para a discussão de política cambial no Brasil. Nesse caso, o papel da política cambial é o de evitar uma apreciação excessiva da taxa de câmbio decorrente das rendas do comércio externo e uma especialização da economia doméstica na produção de bens primários.

Motivo 3. O terceiro motivo para a política cambial é a necessidade de neutralizar as distorções temporárias ou conjunturais provocadas pelo setor financeiro. Essa motivação decorre do questionamento da validade da teoria dos agentes racionais e da hipótese dos mercados eficientes para os mercados de câmbio. O pressuposto é que os agentes têm dificuldades na coleta e no processamento das complexas informações que eles se confrontam e, por isso, instituem regras simples para guiar seu comportamento, que periodicamente são reavaliadas (De Grauwe e Grimalde, 2006). Não se trata de um comportamento irracional dos agentes, mas de um comportamento adequado diante da complexidade do mundo real.

Essas pressuposições se observam na estratégia grafista (ou de análise técnica) usada pelos operadores do mercado de câmbio de forma difundida ${ }^{2}$. A difusão da estratégia grafista, que substitui os modelos que utilizam os fundamentos econômicos para guiar as apostas cambiais, resulta em um mercado não eficiente onde o descolamento entre a taxa de câmbio e os fundamentos é um fenômeno usual. Nesse sentido, o mercado financeiro não leva necessariamente a taxa de câmbio ao equilíbrio, e mostra-se sujeito aos comportamentos de manada, às assimetrias de informação, etc. Cabe à política cambial corrigir essas distorções.

Motivo 4. Mas, no caso brasileiro, as distorções financeiras vão além da volatilidade e também causam tendências cambiais, que se materializam em processos longos de apreciação cambial intercalados com curtos e abruptos períodos de depreciação - como o experimentado nos meses de junho, julho e agosto de 2013. Esse padrão de comportamento da taxa de câmbio é pronunciado na economia brasileira por conta da alta rentabilidade de investimentos financeiros e principalmente das altas taxas de juros praticadas no país.

As operações de carry trade foram uma pressão constante de valorização da moeda brasileira no período recente (Rossi, 2012). Essa operação é um dos principais mecanismos de transmissão do ciclo de liquidez internacional para as taxas de

\footnotetext{
1 "A doença holandesa ou maldição dos recursos naturais pode ser definida como a sobreapreciacão crônica da taxa de câmbio de um país causada por rendas ricardianas que o país obtém ao explorar recursos abundantes e baratos, cuja produção comercial é compatível com uma taxa de câmbio de equilíbrio corrente claramente mais apreciada do que a taxa de câmbio de equilíbrio industrial." (Bresser-Pereira e Gala, 2010, p. 671)

2 "Most firms that actively trade foreign exchange use chartist models - not necessarily exclusively, though some seem to do that, but they are certainly among the tools routinely employed" (Willianson, 2008, 10).
} 
câmbio e consiste em um investimento intermoedas onde se forma um passivo (ou uma posição vendida) na moeda de baixas taxas de juros e um ativo (ou uma posição comprada) na moeda de juros mais altos ${ }^{3}$.

Em um movimento pendular, as operações de carry trade tendem a apreciar as moedas com altas taxas de juros durante a fase ascendente do ciclo de liquidez e depreciá-las na fase de reversão. O detalhe importante é que esse movimento tende a ocorrer de forma assimétrica: o processo de otimismo que caracteriza a expansão da liquidez internacional ocorre de forma mais gradual, enquanto as reversões de humor são usualmente mais abruptas. Como mostram McCauley e McGuire (2009) e Kohler (2010), as moedas que mais se depreciaram no período mais agudo da crise financeira de 2008 foram as mesmas que mais se apreciaram no período anterior à crise, todas elas alvo do carry trade, dentre elas o real. Enquanto as moedas funding, que financiam o carry trade, serviram como porto seguro dos fluxos financeiros, e consequentemente apreciaram na crise $e^{4}$.

Conforme Gagnon e Chaboud (2007), o carry trade de divide em duas categorias: "canonical carry trade" e "derivatives carry trade". No primeiro caso, a posição de carry trade é montada tomando empréstimos em uma moeda e aplicando em ativos denominados em outra, enquanto no segundo, pela formação de posição vendida na moeda de baixos juros e comprada na moeda de altos juros, no mercado de derivativos. Em particular, o segundo caso mostra-se extremamente relevante para a economia brasileira e condiciona o uso das políticas cambiais, conforme será desenvolvido nas próximas seções.

\section{ESPECULAÇÃO NO MERCADO FUTURO BRASILEIRO}

O mercado de derivativos é de grande importância para a atividade econômica na medida em que propicia o hedge cambial e assim reduz as incertezas microeconômicas, inerentes ao processo produtivo. Contudo, esse mercado apresenta um caráter dual; ao mesmo tempo em que ele reduz incertezas microeconômicas dos agentes que buscam hedge, ele potencialmente aumenta as instabilidades macroeconômicas (Farhi, 1998). Em particular, o mercado de derivativos se torna disfuncional para o desenvolvimento econômico quando a especulação e a arbitragem se tornam as motivações dominantes para a operação desse mercado. Esta seção argumenta que o mercado futuro de câmbio brasileiro se enquadra nessa perspectiva.

Os contratos de derivativos são contratos bilaterais em que um agente assume a

\footnotetext{
${ }^{3}$ Alguns autores consideram uma definição mais ampla de carry trade na qual a operação prescinde de uma alavancagem do agente e da aplicação em ativos que rendem juros: "Indeed, a useful, still broader definition of the carry trade would cover any investment strategy that involved shifting out of lowinterest-rate assets and into anything else - emerging market debt, equities, real estate, commodities, and the like" (Frankel, 2008, p. 38).

${ }^{4}$ É interessante notar que, no auge da fuga para liquidez da crise de 2008, a moeda japonesa foi a única que se apreciou em relação ao dólar americano. Para McCauley e McGuire (2009) e Kohler (2010) a explicação está no seu papel como moeda funding do carry trade.
} 
ponta comprada e outro agente assume a ponta vendida. Nesse sentido, o predomínio da especulação em um mercado de derivativos não é necessariamente nocivo para a atividade econômica, uma vez que os especuladores podem se colocar em pontas opostas e assim neutralizar a formação de uma tendência de preço. Contudo, o problema ocorre quando a especulação é unidirecional, como já alertava Keynes:

"But there is a further contingency of considerable importance which occurs when speculation is exceptionally active and is all one way. [...] It is interesting to notice that when the difference between forward and spot rates has become temporarily abnormal, thus indicating an exceptional pressure of speculative activity, the speculators have often turned out to be right" (Keynes, 1924, pp. 129-130)

No mercado de câmbio brasileiro, o padrão de formação de posições em dólar futuro coloca, de um lado, os bancos, e no lado oposto, os estrangeiros e investidores institucionais nacionais (Figura 2$)^{5}$. Ou seja, quando os primeiros estão com posições líquidas compradas em dólar futuro, os últimos assumem a posição vendida, e vice-versa.

A análise da Figura 2 sugere que essa formação de posições também parece ter relação como movimento da taxa de câmbio. No período de apreciação do real, entre julho de 2010 e julho de 2011, estrangeiros e investidores institucionais formam posição vendida em dólar futuro, ou seja, na perspectiva do especulador, apostaram na direção correta, a da apreciação da moeda brasileira. Já os bancos se posicionaram na ponta contrária. Nesse período, a posição vendida líquida desses primeiros agentes chegou a US\$ 20 bilhões, em outubro de 2010.

Figura 2: Padrão de formação de posições líquidas no mercado futuro

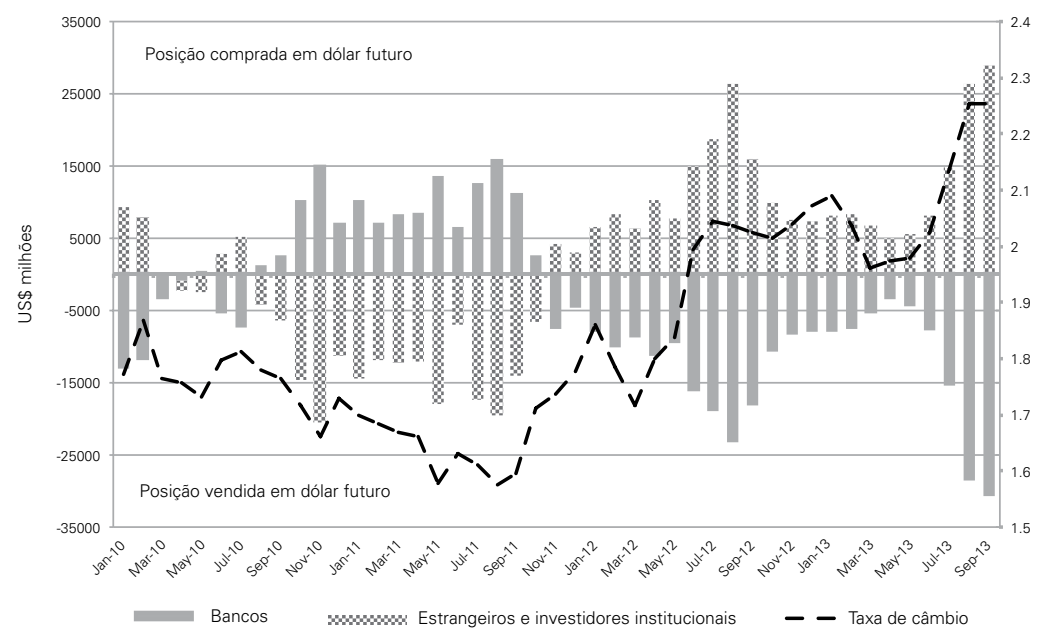

Fonte: BM\&F e Banco Central do Brasil. Elaborado pelo autor.

\footnotetext{
${ }^{5}$ As empresas não financeiras e as pessoas físicas têm participação muito pequena nesse mercado.
} 
A partir de julho de 2011, mês do IOF sobre as posições vendidas e também mudanças no cenário da crise internacional, os estrangeiros e investidores institucionais reduzem a posição vendida e passam a assumir posições compradas em dólar futuro. Essa mudança de posição coincide com a mudança de trajetória da taxa de câmbio, que passa a se depreciar, a partir do mês de julho de 2012 até setembro de 2013. Adicionalmente, no primeiro semestre de 2013, quando a depreciação do real se torna mais aguda, verifica-se um grande aumento da posição comprada em dólar futuro de estrangeiros e investidores institucionais, que somadas superaram US\$ 25 bilhões nos meses de julho e agosto, em contrapartida, a posição vendida dos bancos que também bateu recordes.

As evidências da especulação no mercado futuro ficam mais nítidas com os gráficos de dispersão que analisam a correlação entre a variação da posição desses dois grupos de agentes e a variação da taxa de câmbio, em periodicidade mensal, entre janeiro de 2010 e setembro de 2013 (Figura 3) ${ }^{6}$. Antes dessa análise, deve-se ter em conta que o uso de derivativos com a finalidade estrita de hedge não deve ser motivado por uma visão direcional da taxa de câmbio. Para o hedge, os agentes procuram o mercado futuro para cobrir posições assumidas no mercado à vista, que independem de expectativas quanto à taxa de câmbio no futuro. Para esses agentes não há, portanto, motivos para variação de posições no mercado futuro conforme varia a taxa de câmbio ${ }^{7}$.

Contudo, a Figura 3 mostra que a formação de posição no mercado futuro dos agentes estrangeiros e dos investidores institucionais acompanha a tendência cambial no intervalo de um mês. Nos meses de apreciação da moeda brasileira esses agentes estão formando posições vendidas em dólar futuro, enquanto nos meses de depreciação da moeda brasileira há formação de posições compradas em dólar futuro. Já os bancos têm o comportamento oposto.

Com relação aos bancos, seria ingênuo supor que esses perdem sistematicamente ao formarem posições no mercado futuro. O que os dados apontam é que esses agentes tomam a ponta contrária dos estrangeiros e investidores institucionais fundamentalmente para arbitrar entre os mercados à vista e futuro. Como a operação de arbitragem pressupõe duas operações equivalentes e contrárias nos mercados à vista e futuro, explica-se por que a variação da posição em dólar futuro dos bancos está negativamente correlacionada com a taxa de câmbio. Ou seja, uma compra de dólar futuro por parte dos bancos está associada a uma apreciação da taxa de câmbio à vista, uma vez que esses agentes vendem dólar à vista e, simultaneamente, compram dólar futuro.

\footnotetext{
${ }^{6}$ Essa metodologia para análise da taxa de câmbio foi aplicada por Klitgaard e Weir (2004) para o mercado futuro de câmbio de Chicago.

${ }^{7}$ Pode-se pensar em um fator que provoque um aumento da necessidade de hedge e ao mesmo tempo uma apreciação cambial como, por exemplo, uma entrada maciça de investidores estrangeiros no mercado à vista, por exemplo, para adquirir imóveis brasileiros. Entretanto, o sentido da correlação seria o oposto ao apresentado neste trabalho: a apreciação cambial estaria associada ao aumento de posições compradas em dólar futuro, e não vendidas como de fato ocorre.
} 
Figura 3: Formação de posição dos agentes em dólar futuro e variação cambial*
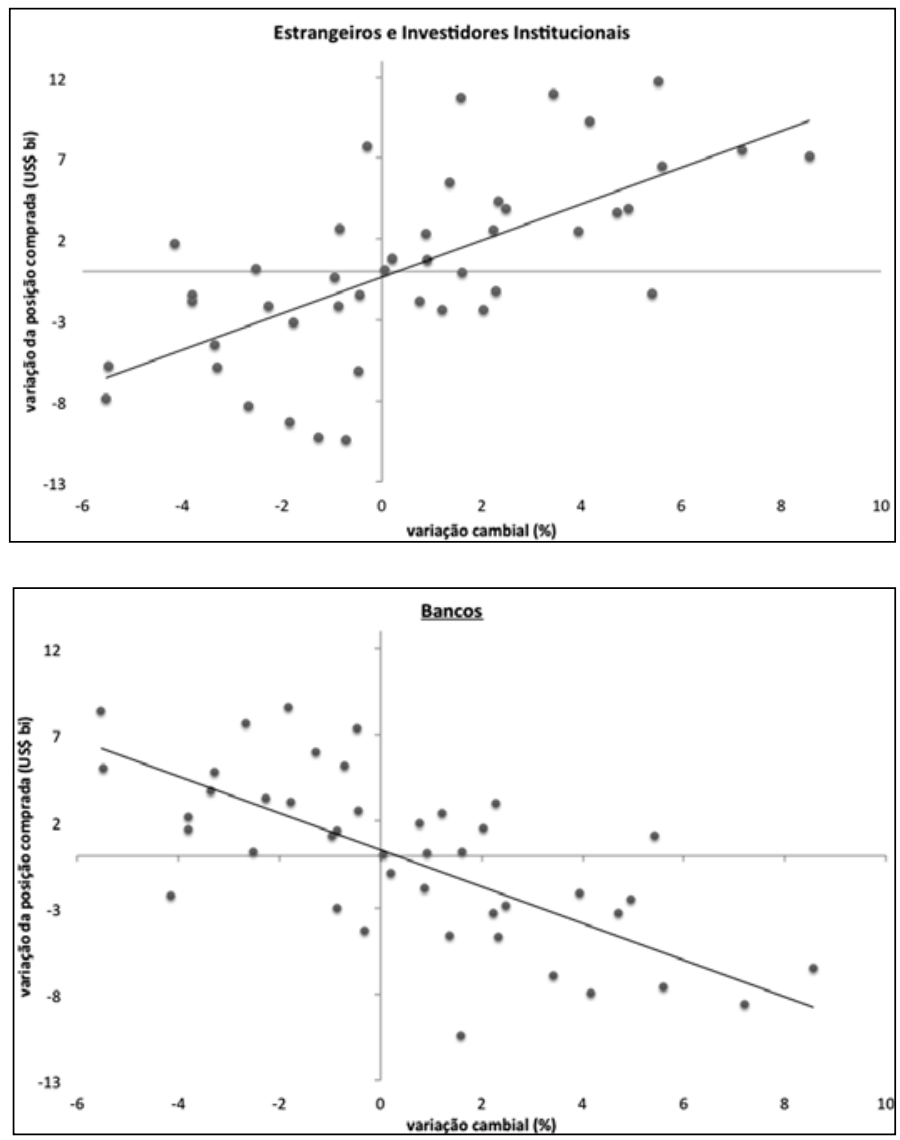

Fonte: BM\&F e Banco Central do Brasil. Elaborado pelo autor.

* Os gráficos contêm observações que associam as variações mensais da taxa de câmbio (PTAX) com a variação da posição dos agentes mensal nos mercados de dólar futuro e de cupom cambial (DDI) entre janeiro de 2010 e setembro de 2013, calculadas com base no dia 15 de cada mês ou no primeiro dia útil subsequente.

Desses dados, decorrem duas hipóteses de interpretação. A primeira é que esses agentes causam as tendências de variação cambial no mercado à vista. Nesse caso, a exposição líquida no mercado futuro seria a origem dos ciclos cambial e da volatilidade conjuntural. Já a segunda hipótese é que esses agentes reagem aos movimentos de câmbio depois do fato ocorrer. Nesse caso, esses agentes teriam um comportamento típico de "seguidor de tendência", e estariam contribuindo para reforçar uma apreciação ou depreciação e a volatilidade já em curso. Em ambos as possibilidades a especulação exerce um papel ativo sobre a formação da taxa de câmbio brasileira.

Em síntese, esses resultados assinalam que os estrangeiros e investidores institucionais formam ou acentuam tendências de preço no mercado de câmbio futuro 
com o objetivo de obter ganhos especulativos e que os bancos atuam para realizar ganhos de arbitragem transmitindo a pressão especulativa oriunda do mercado futuro para o mercado à vista. A próxima seção explora as mediações entre esse circuito especulação-arbitragem e a institucionalidade do mercado de câmbio brasileiro e, a partir daí, o papel da política cambial.

\section{POLÍTICA CAMBIAL E INSTITUCIONALIDADE DO MERCADO DE CÂMBIO ${ }^{8}$}

Uma vez discutidos os motivos para a uma política cambial ativa e a especulação no mercado futuro brasileiro, a etapa seguinte consiste em entender a implementação e os efeitos das políticas cambiais. Esse entendimento passa primeiramente pelo reconhecimento das especificidades do mercado de câmbio brasileiro e pela caracterização de sua institucionalidade. As características de funcionamento do mercado de câmbio condicionam a eficácia dos instrumentos de política cambial que não são eficazes ou ineficazes por natureza, mas dependem do conjunto da operação do mercado. Ou seja, uma política concebida e aplicada de forma isolada tendo em vista apenas uma parte do mercado de câmbio pode estar fadada a ser neutralizada, dada a complexidade do mercado cambial no Brasil. Nesse sentido, a política cambial deve ser pensada de forma integrada, considerando toda a institucionalidade do mercado de câmbio brasileiro.

\section{Mercado primário e a política cambial}

A Figura 4 mostra um esquema parcial do mercado de câmbio que restringe o seu funcionamento a um problema de oferta e demanda por divisas pelos agentes primários, residentes e não residentes (exportadores, importadores, investidores financeiros, etc.) que selam contratos de câmbio de compra e venda de dólar que em seu conjunto definem o conceito de fluxo cambial contratado.

Ao considerar isoladamente o mercado primário, a formação da taxa de câmbio depende do fluxo cambial líquido que resulta das relações comerciais e financeiras dos agentes primários. Nesse contexto, a política cambial é concebida para administrar o excesso ou a escassez do fluxo de divisas. Assim, o efeito de um fluxo cambial positivo (negativo) sobre a taxa de câmbio pode ser neutralizado através da compra (venda) de reservas cambiais pelo banco central ou através de uma política de regulação da entrada (saída) dos fluxos de capital. No primeiro caso, a política de intervenções exige a administração de reservas cambiais, cujo estoque

\footnotetext{
${ }^{8}$ Sobre a descrição da operacionalidade do mercado de câmbio brasileiro ver Rossi (2012), Carneiro e Rossi (2012), Prates (2009) e Souza e Hoff (2006) para o conjunto do mercado, Garcia e Urban (2004) para o mercado interbancário, Dodd e Griffith-Jones (2007) e Farhi (2010) para o mercado de derivativos no Brasil.
} 


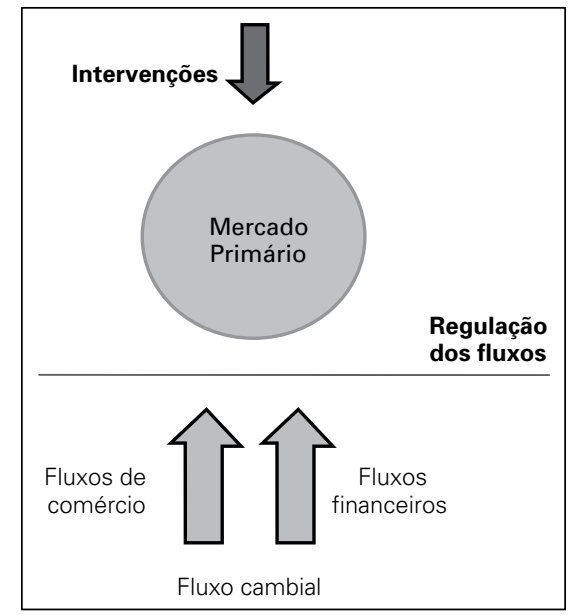

Fonte: Elaborado pelo autor.

implica custos fiscais elevados para a economia brasileira; já no segundo caso, os instrumentos de regulação não implicam custo fiscal e, em alguns casos, como nos de aplicação do IOF, geram benefícios para os cofres públicos.

Contudo, essa concepção da política cambial, limitada a uma política de intervenção no mercado primário e de regulação dos fluxos de capital, não somente é estreita, mas é particularmente inadequada para as especificidades do mercado de câmbio brasileiro.

A Figura 5 mostra que, entre 2006 e 2013, a política de intervenções do Banco Central do Brasil foi pautada, grosso modo, pela absorção do fluxo cambial através da compra de reservas ou pelo fornecimento de liquidez ao mercado através da venda de dólares". A despeito da "neutralização" do fluxo cambial, a taxa de câmbio foi bastante volátil nesses anos e passou por ciclos de apreciação e depreciação ${ }^{10}$. Nesse sentido, o fluxo cambial não explica os movimentos da taxa de câmbio real/ dólar no período recente, tampouco a taxa câmbio pode ser administrada por uma política cambial restrita às intervenções e a regulação dos fluxos de capital.

\section{Mercado futuro e interbancário: o circuito especulação-arbitragem}

Há dois outros elementos importantes no mercado de câmbio brasileiro que devem ser considerados para uma análise completa da política cambial: o mercado de derivativos e o mercado interbancário de câmbio.

\footnotetext{
${ }^{9} \mathrm{O}$ saldo do fluxo cambial desse período foi de US\$ 261 bilhões enquanto a acumulação líquida de reservas decorrente das intervenções foi de US\$ 256 bilhões.

${ }^{10} \mathrm{O}$ ano de 2013 foge do padrão observado. Nesse ano, há uma clara mudança de estratégia do banco central em priorizar as intervenções com swaps cambiais.
} 
Figura 5: O fluxo cambial mensal e as intervenções do Banco Central

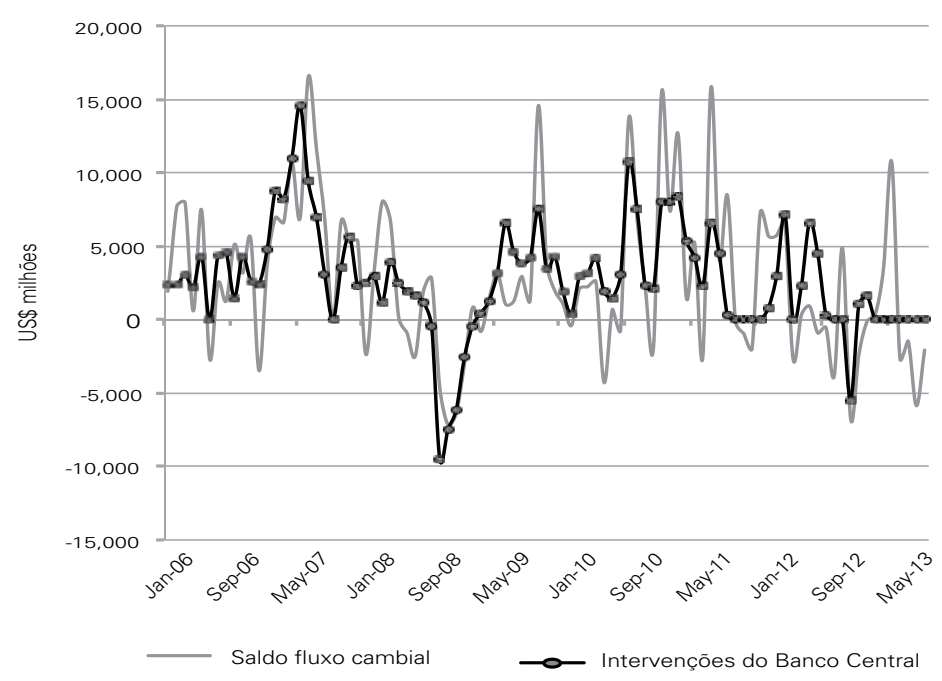

Fonte: Banco Central do Brasil. Elaborado pelo autor.

Uma característica fundamental do mercado de câmbio brasileiro é a assimetria de liquidez entre a negociação de reais à vista, nos mercados primário e interbancário, e de derivativos, essencialmente o mercado de dólar futuro da BM\&F (Figura 6). Medida pelo giro financeiro diário médio do mês de agosto de 2013, a liquidez do mercado futuro foi em média de US\$ 27 bilhões por dia, em torno de quatro vezes maior do que negociação no mercado à vista, de US\$ 6,4 bilhões por dia ${ }^{11}$.

Por conta dessa assimetria de liquidez, a taxa de câmbio se forma primeiro no mercado futuro e é transmitida por arbitragem para o mercado à vista. Essa é uma visão difundida entre os operadores de mesa de câmbio do mercado financeiro, fato que é tomado como "intuitivo", uma vez que a liquidez se concentra nesse mercado e por conta do mercado tomar a taxa futura como referência para a cotação dos demais mercados ${ }^{12}$. O trabalho de Ventura e Garcia (2009) conclui que a cotação da taxa de câmbio se forma primeiro no mercado futuro, sendo então transmitida por arbitragem para o mercado à vista com defasagens de 10 minutos. Outros autores sustentam a posição de que a taxa de câmbio se forma no futuro, como Franco (2000) e Dodd e Griffith-Jones (2007); esses últimos argumentam com base em entrevistas.

Um dos principais motivos para essa assimetria de liquidez é uma assimetria

\footnotetext{
${ }^{11}$ Dados da BM\&F e do Banco Central do Brasil. Para o mercado à vista somaram-se os contratos de compra e venda de câmbio comercial e financeiro e o giro no mercado interbancário medido pelo volume da clearing da BM\&F. Para o mercado interbancário não há registro das negociações que ocorrem no mercado de balcão, mas sabe-se que a grande maioria dos negócios ocorrem na BM\&F.

${ }^{12}$ Rossi (2012) explora esse aspecto com base em entrevistas junto a agentes financeiros.
} 

(giro financeiro em agosto de 2013)

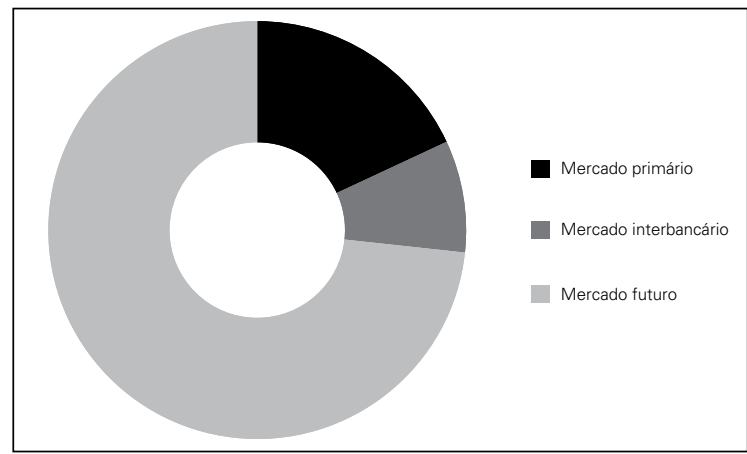

Fonte: BM\&F e Banco Central do Brasil. Elaborado pelo autor.

regulatória, entre esses mesmos mercados. A formação de posições no mercado de câmbio à vista é restrita a instituições bancárias e corretoras especializadas, que devem ter autorização do Conselho Monetário Nacional e suas operações formalizadas em contratos de câmbio e registradas no SISBACEN ${ }^{13}$. Já no mercado futuro da BM\&F qualquer agente pode formar posições abertas em dólar futuro, desde que cadastrado no sistema dessa instituição ${ }^{14}$. As menores exigências regulatórias e a facilidade de acesso condicionam a atuação dos agentes do mercado de câmbio ${ }^{15}$ e a atraem investidores estrangeiros para a negociação da moeda brasileira no mercado futuro. Para Prates (2009), a existência de um mercado futuro líquido de reais atrai investidores interessados, não propriamente na moeda brasileira, mas em ativos com características similares ao real:

"Esse número recorde também está relacionado ao fato de alguns investidores globais utilizarem esses contratos como uma proxy de derivativos de moedas emergentes, que são altamente correlacionadas ao real (como a lira turca e o rand sul-africano), mas não possuem mercados de derivativos organizados líquidos e profundos” (Prates, 2009, p. 267).

No mercado de dólar futuro brasileiro não há negociação de dólares. Negocia-se

\footnotetext{
${ }^{13}$ Em 20/09/2013, 190 instituições estavam autorizadas a operar no mercado de câmbio.

${ }^{14}$ Para os estrangeiros, a operação na BM\&F depende da abertura de uma "conta 2689" para constituição de margens de garantia para as operações. Esse nome faz alusão à resolução do Banco Central 2689, de janeiro de 2000, que permite aplicações dos estrangeiros nos mercados de derivativos, ações e renda fixa sem restrições quanto ao tipo de operação e sem limite de posição.

15 “Os participantes do mercado interbancário de câmbio passaram a privilegiar o mercado de derivativos para realizar suas operações indexadas à taxa de câmbio, deixando o mercado interbancário apenas para suprir suas necessidades em moeda estrangeira, para liquidar operações do mercado primário" (Garcia e Urban, 2004, p. 12).
} 
o valor em reais da variação de uma determinada quantidade de dólares em relação à moeda brasileira. Como as operações são liquidadas em reais, não há contratos de câmbio, tampouco movimentação de divisas, e, portanto, a legislação cambial, que condiciona a negociação de divisas no mercado à vista, não se aplica a esse mercado.

O mercado futuro está ligado ao mercado à vista por relações de arbitragem ${ }^{16}$. Os preços futuros, além de riscos e expectativas, expressam essas condições de arbitragem. O preço do dólar futuro, por exemplo, não é o preço esperado do dólar no futuro ${ }^{17}$. No caso brasileiro, o dólar futuro está sistematicamente acima do dólar à vista devido ao diferencial entre os juros brasileiros e os juros externos ${ }^{18}$.

O termômetro para arbitragem entre o mercado futuro e à vista é o cupom cambial. Essa variável pode ser definida como a taxa de juros em dólar no mercado brasileiro ${ }^{19}$. O cupom cambial aumenta quando o preço do dólar futuro se aproxima do preço do dólar à vista, e se reduz quando eles se distanciam. A intuição por detrás disso está no fato de que quando há um excesso de oferta de dólar no mercado futuro o hedge cambial fica mais barato e assim as aplicações em dólar onshore, com cobertura cambial, ficam mais bem remuneradas ${ }^{20}$.

Figura 7: Ilustração do circuito especulação-arbitragem

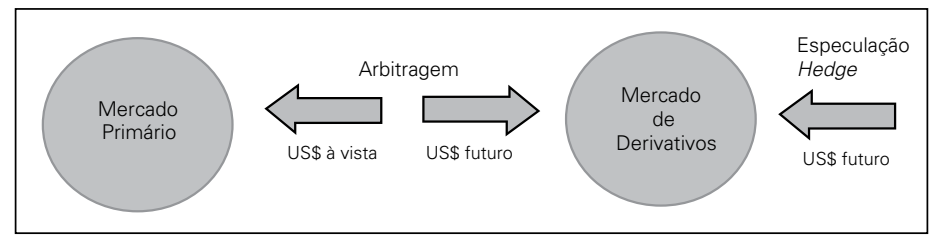

Fonte: BM\&F e Banco Central do Brasil. Elaborado pelo autor.

O importante é notar que o circuito especulação-arbitragem se inicia com um excesso de oferta ou de demanda no mercado futuro e a partir daí dá origem a

\footnotetext{
${ }^{16}$ A operação de arbitragem é caracterizada por duas operações simultâneas, uma no mercado à vista e outra a termo, onde a motivação é de explorar distorções de preço entre as cotações nos dois mercados e obter ganhos sem risco.

${ }^{17}$ A análise de Keynes (1924) foi pioneira ao tratar esse aspecto.

${ }^{18}$ A relação entre o taxa de câmbio futura e a taxa de câmbio à vista é dada pela paridade coberta conforme a equação $e_{\mathrm{f}}=\mathrm{e}_{\mathrm{s}}\left(1+\mathrm{i}^{\mathrm{d}}\right) /\left(1+\mathrm{i}^{*}\right)$, que tem como variáveis a taxa de câmbio spot $\left(\mathrm{e}_{\mathrm{s}}\right)$, a taxa de câmbio no mercado futuro $\left(\mathrm{e}_{\mathrm{f}}\right) \mathrm{e}$ as taxas de juros internacional e doméstica i* e id.

${ }^{19} \mathrm{O}$ cupom cambial é usualmente definido como a diferença entre a taxa de juros interna e a expectativa de depreciação da taxa de câmbio do país. Essa definição é enganosa pois só se verifica se for válida a paridade descoberta de juros. Em outras palavras, se for aceito que o diferencial de juros entre aplicações em reais e em dólar traz embutido uma expectativa dos agentes quanto à depreciação da moeda brasileira. Nesse caso, a cotação do dólar futuro seria um bom previsor da cotação do real no futuro. Contudo, é extensa a literatura econômica que mostra que essa paridade não se verifica. A violação da paridade descoberta de juros foi batizada de forward premium puzzle. Sobre a literatura que trata desse assunto, ver Sarno e Taylor (2006).
}

${ }^{20}$ Sobre os aspectos técnicos da formação do cupom cambial, ver Rossi (2012). 
arbitragem entre os mercados (Figura 7). No caso de um excesso de oferta de dólares futuros, por exemplo, o cupom cambial aumenta o que torna as aplicações em dólar onshore convidativas quando comparadas às taxas de captação offshore. Isso abre espaço para arbitradores que assumem a ponta comprada do mercado futuro e, ao mesmo tempo, tomam recursos no exterior para vender dólares no mercado doméstico ${ }^{21}$. Por conseguinte, o excesso de oferta de dólares por parte dos arbitradores tende a apreciar a taxa de câmbio à vista.

No Brasil, a arbitragem é realizada fundamentalmente pelos bancos, que são autorizados pelo Conselho Monetário Nacional a atuar no mercado interbancário de câmbio. Essa se realiza por meio das operações de "linha interbancária internacional”, que são as únicas operações de câmbio entre residentes e não residentes que não exigem contrato de câmbio, logo não constam no fluxo cambial. Essa captação de recursos tampouco está sujeita aos controles de capitais que porventura incidem sobre os agentes primários ${ }^{22}$.

$\mathrm{Na}$ prática, esses recursos são a contraparte do saldo dos agentes primários ou das intervenções do banco central e resultam na acumulação de posição dos bancos, conforme a equação:

$$
\mathrm{FC}_{t}=\mathrm{IBC}_{t}+\Delta \mathrm{PB}_{t}+\mathrm{Aj}_{t}
$$

onde $\mathrm{FC}_{t}$ é o fluxo cambial contratado no período $t, \mathrm{IBC}_{t}$ são as intervenções do banco central no mercado à vista no período $t$ decorrentes de compras e vendas no mercado, $\Delta \mathrm{PB}_{t}$ é a variação da posição comprada em dólares dos bancos no período $t$ e $\mathrm{Aj}_{t}$ é uma variável de ajustes ${ }^{23}$.

Considerando essa equação, a estratégia dos bancos em variar seu estoque de divisas pode ser extremamente relevante para a formação da taxa de câmbio, assim como o fluxo cambial. Pode haver situações em que o fluxo cambial líquido de divisas seja importante, mas o real se deprecia, já que os bancos querem aumentar a posição comprada em dólares. Ou seja, os dólares do mercado são disputados pelos bancos que oferecem preços melhores pela moeda americana para os agentes primários e no interbancário, o que deprecia o real. A situação oposta ocorre quando não há fluxo positivo de divisas, mas os bancos querem se livrar de posições compradas em dólar ou aumentar sua posição vendida. Nesse caso, seguindo raciocínio homólogo, a taxa de câmbio do real se aprecia.

Em síntese, há três pontos relevantes já tratados: 1) o movimento da taxa de câmbio não está necessariamente ligado ao fluxo de câmbio; 2) a estratégia dos bancos quanto à formação de posição de câmbio é um elemento importante para a formação da taxa de câmbio; e 3) essa estratégia dos bancos quanto à posição

\footnotetext{
${ }^{21}$ Com isso, o agente fica comprado em dólar futuro e vendido em dólar à vista, o que equivale a estar "aplicado" em cupom cambial.

${ }^{22} \mathrm{O}$ fator gerador de IOF é o contrato de câmbio, o que constitui um empecilho técnico para a aplicação do imposto nas operações de linha.

${ }^{23}$ Os ajustes referem-se a alguma operação de câmbio desfeita, ou seja, contratada, mas não liquidada.
} 
cambial depende da arbitragem que realizam e da pressão especulativa no mercado de dólar futuro. Nesse sentido, os bancos, guiados pelo mercado futuro, representam uma fonte relativamente autônoma de oferta e demanda de divisas para o mercado primário.

\section{Política cambial: esquema analítico}

Ao considerar o mercado futuro e o mercado interbancário, a operação da política cambial pode ser esquematizada conforme a Figura 8. Nesse contexto, a atuação do banco central restrita ao mercado à vista pode ser pouco eficaz, pois, por um lado, ela afeta a cotação da taxa de câmbio à vista ao absorver ou prover liquidez no mercado, mas, por outro, ela não afeta diretamente o circuito especulação-arbitragem que, dependendo da intensidade, pode perdurar mesmo com intervenções sistemáticas do banco central.

Figura 8: Mercado de câmbio e a política cambial

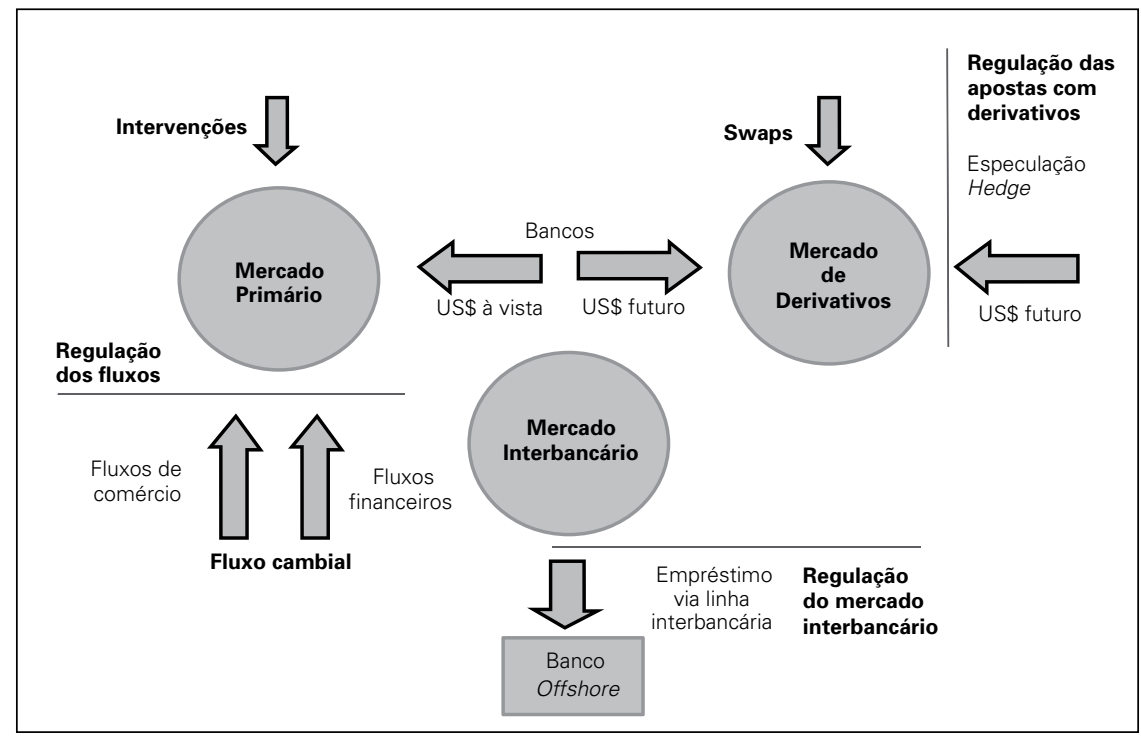

Fonte: Elaborado pelo autor.

Já a atuação com swaps cambiais tem a vantagem de afetar diretamente o mercado onde se forma a taxa de câmbio e se origina a especulação. O objetivo desse instrumento é influir na formação da taxa futura e assim evitar a contaminação da taxa de câmbio à vista. Essa atuação pode afetar o circuito especulação-arbitragem uma vez que o banco central faz a contraparte do especulador, tirando o arbitrador da operação, o que evita a variação da posição dos bancos. E, ao absorver ou prover liquidez em dólar futuro, o banco central também ameniza a variação do cupom cambial. Contudo, os leilões de swaps também podem conviver passivamente com a especulação cambial e nos momentos mais críticos, de forte 
formação de posições especulativas, podem não ter o efeito desejado sobre a taxa de câmbio.

No Brasil, particularmente nos ciclos de apreciação cambial anterior (2003-2008) e posterior (2009-2012) à crise financeira de 2008, o banco central foi parte integrante do circuito especulação-arbitragem, pois não agiu diretamente sobre as causas da apreciação cambial da moeda brasileira, apesar de amenizar os efeitos. $\mathrm{Na}$ altura, dadas as especificidades do mercado de câmbio brasileiro, a política cambial exigia uma abrangência maior para conter os ciclos de apreciação.

As autoridades de política cambial brasileira demoraram para endereçar a natureza do problema do mercado de câmbio e da formação da taxa de câmbio. Até 2011, a política cambial se restringiu à regulação dos fluxos de capital e às intervenções nos mercados à vista e de derivativos, com os swaps reversos e tradicionais. Já em janeiro de 2011, o banco central atuou sobre a estrutura regulatória do mercado interbancário e impôs custos às posições vendidas dos bancos ${ }^{24}$. Essa regulação teve efeito direto sobre o circuito especulação-arbitragem, uma vez que aumentou o custo de captação dos bancos pelas linhas interbancárias e modificou a formação do preço do dólar futuro, aumentando o cupom cambial e onerando também a especulação no mercado futuro ${ }^{25}$.

Em julho de 2011, o governo direcionou a política cambial para a regulação do mercado de derivativos. Através da Medida Provisória 539, ficou possibilitada a determinação de depósitos sobre os valores nocionais dos contratos, fixar limites, prazos e outras condições sobre as negociações dos contratos. Além disso, institui-se um imposto de $1 \%$ sobre o valor nocional das operações que resultem em aumento da exposição líquida vendida dos agentes ${ }^{26}$. Essa medida atingiu o cerne da especulação cambial que vinha ocorrendo até então pela apreciação da moeda brasileira.

Com essas medidas de política cambial, somadas aos IOF sobre fluxos financeiros, montou-se uma institucionalidade capaz de evitar a apreciação e reduzir a volatilidade da moeda brasileira e de administrar a taxa de câmbio. Essa capacidade de administração da taxa de câmbio pode ser observada no segundo semestre de 2012, em particular entre 04/07 e 12/11 de 2012, quando a taxa de câmbio flutuou no intervalo entre R $\$$ US $\$ 2,00$ e 2,05, o que constitui sua menor volatilidade desde o abandono do regime de bandas cambiais em 1999. As medidas regulatórias instituídas sobre o mercado de derivativos e o mercado interbancário reduziram a especulação pela apreciação do real e permitiram ao banco central o manejo da taxa de câmbio com intervenções (vendas e compras) e swaps (tradicional e reverso), que mostraram impacto mais efetivo na formação da taxa de câmbio e na dissuasão do mercado financeiro em suas empreitadas especulativas. Nesse curto período, o real se desgarrou do ciclo de liquidez e deixou de estar correlacio-

\footnotetext{
${ }^{24}$ Circular 3.520.

${ }^{25}$ Sobre os aspectos técnicos dessa mudança, ver Rossi (2012).

${ }^{26}$ Decreto 7.536 .
} 
nado com outras moedas, com o índice de commodities e com outras variáveis financeiras.

Contudo, a eficiência desse aparato regulatório foi restrita a conter a especulação pela apreciação da moeda brasileira e nada dificultou a montagem do circuito especulação-arbitragem na direção inversa, no sentido da depreciação do real, estruturado a partir das posições compradas em dólar futuro. Tampouco essas medidas de política cambial assinalaram para uma regulação mais profunda do mercado de câmbio que permita diminuir substancialmente a assimetria de liquidez e a atividade especulativa no mercado futuro. A seção seguinte retoma as diretrizes gerais para uma "reforma" no mercado de câmbio e conclui o artigo.

\section{Box 1: Sobre o mercado de reais offshore}

O mercado de reais offshore consiste no espaço de negociação de reais entre não residentes, em jurisdição estrangeira ${ }^{27}$. Segundo o BIS (Bank of International Settlements), em abril de 2013 70\% dos contratos com a moeda brasileira ocorreram no mercado offshore ${ }^{28}$. O funcionamento desse mercado é condicionado pela inconversibilidade da moeda brasileira ${ }^{29}$ que faz com que os reais negociados no exterior sejam liquidados em moeda estrangeira. Logo, não há clearing em reais de contratos de câmbio fora do Brasil que exerça influência direta sobre o mercado de câmbio à vista. Dito isso, vale reforçar que a formação da taxa de câmbio à vista do real, diferentemente de moedas centrais do sistema, é um fenômeno exclusivamente onshore. Entretanto, isso não isenta o mercado offshore de reais de influência importante na formação da taxa de câmbio futura.

Os mercados offshore não existem isoladamente, há instituições que operam nesse mercado que mantêm vínculos constantes com o mercado onshore. A influência desse mercado na formação da taxa de câmbio depende do balanço de operações vendidas e compradas realizadas nessa jurisdição. Como propõe He e McCauley (2010), é importante distinguir o caráter simétrico ou assimétrico do uso de uma moeda offshore. No uso simétrico, os agentes comprados e vendidos em uma moeda se neutralizam e não há pressão desse mercado sobre a taxa de câmbio onshore. Já no uso assimétrico, o mercado offshore é sistematicamente mais usado para uma das pontas da operação:

\footnotetext{
${ }^{27}$ Nota-se que o conceito de mercado offshore empregado não se define pelo parâmetro geográfico. Os residentes no país que operam no exterior devem obedecer às prescrições da jurisdição brasileira. No caso de uma operação de NDF (Non Deliverable Forward) no exterior, entre um residente e um não residente, essa deve ser registrada em um órgão competente, e a rigor consiste em uma operação onshore.

${ }^{28}$ Esses dados podem ser consultados na pesquisa "Triennial Central Bank Survey of foreign exchange and derivatives market activity" do BIS.

${ }^{29}$ A exemplo de Carneiro (2008), consideramos como inconversibilidade o não desempenho das funções da moeda no âmbito internacional. Na prática, estamos nos referindo à inexistência do uso da moeda brasileira como meio de pagamento que liquida contratos offshore.
} 
vendida ou comprada. Nesse último caso, as instituições que operam simultaneamente nos dois mercados ajustam suas posições de câmbio no mercado onshore, e com isso transmitem a pressão compradora ou vendedora para esse mercado. No caso brasileiro, essas posições são cobertas fundamentalmente na BM\&F.

Para tornar mais claro o argumento, cabe uma ilustração da forma operação de um banco offshore. Esse oferece um fundo com rendimento atrelado à moeda brasileira, ou um contrato de NDF (Non Deliverable Forward) em reais, a um cliente que fica vendido em dólares e comprado em reais enquanto o banco assume a ponta contrária. Logo, o cliente aufere diferencial de juros e ganha com a apreciação da moeda brasileira enquanto o banco paga o diferencial de juros e ganha com a depreciação do real. Para fazer hedge dessa operação, o banco recorre ao mercado onshore e vende dólares futuros na BM\&F. A predominância de agentes com posições vendidas em reais no mercado offshore leva, portanto, a ajustes de posições no mercado onshore e transmite pressões para apreciação da taxa de câmbio do real.

A despeito de estar fora da jurisdição das autoridades brasileiras, o mercado offshore é afetado pela política cambial doméstica. A regulação sobre o mercado onshore tende a encarecer as operações de arbitragem onshore-offshore e assim desestimular as especulação no mercado offshore. Nesse sentido, o mercado offshore impulsiona o circuito especulação-arbitragem, estabelece novos desafios para a política cambial, mas não compromete da regulação do mercado de câmbio doméstico. Nesse ponto, vale ressaltar que uma regulação pontual e isolada no mercado de derivativos domésticos pode transferir esse mercado para o exterior e não ter efeito sobre a dinâmica cambial, contudo, uma regulação ampla que trate também dos canais de arbitragem é eficaz sobre a dinâmica cambial e penaliza a especulação, tanto onshore, quanto offshore.

\section{CONSIDERAÇÕES FINAIS}

Esse artigo avaliou que a formação da taxa de câmbio no Brasil não depende apenas do fluxo cambial, mas trata-se também de um problema de estoque de divisas no mercado interbancário e de apostas no mercado futuro. Destacou-se que o mercado de câmbio brasileiro tem como especificidade uma assimetria de liquidez e de regulação entre os mercados futuro e à vista que o torna extremamente permeável à especulação financeira. De forma recorrente, o protagonismo do mercado futuro condiciona a volatilidade e as tendências cambiais. Períodos de especulação unidirecional e arbitragem ininterrupta submetem a formação da taxa de câmbio brasileiro à formação de expectativas dos agentes financeiros.

Essa dinâmica especulativa constitui um desafio para a elaboração e implementação de políticas cambiais. Os instrumentos usuais de atuação no mercado de câmbio, como as intervenções e os swaps, apesar de importantes, não são suficientes para mitigar a volatilidade e as tendências de preços gerados pelo setor finan- 
ceiro. O desafio da política cambial é, portanto, mais complexo e exige um olhar transformador sobre a atual institucionalidade do mercado de câmbio.

Nesse sentido, uma taxa de câmbio menos volátil e mais adequada para o desenvolvimento econômico brasileiro passa por mudanças na institucionalidade do mercado de câmbio. Em particular, essas mudanças dependem de uma regulação do mercado de derivativos que permita reduzir as posições especulativas nesse mercado, associadas principalmente aos estrangeiros e aos investidores institucionais nacionais, conforme identificado neste trabalho. Essa regulação, por sua vez, passa por uma inevitável redução da liquidez desse mercado e por uma transferência gradual de liquidez para o mercado à vista, que pode ser ampliado tanto no que se refere aos atores relevantes, quanto no que se refere aos instrumentos.

Por fim, a transição para um padrão de flutuação cambial menos volátil e mais adequado ao crescimento é uma opção política que se apresenta como crucial para as necessidades brasileiras, uma vez que um padrão de flutuação instável e sujeito a distorções financeiras é incompatível com o desenvolvimento econômico.

\section{REFERÊNCIAS BIBLIOGRÁFICAS}

Bresser-Pereira, L.C. (2008) “The Dutch disease and its neutralization: a ricardian approach", Revista de Economia Politica, v. 28, n. 1 (109), pp. 47-71.

Bresser-Pereira, L.C. \& Gala, P. (2010) “Macroeconomia estruturalista do desenvolvimento", Revista de Economia Política, v. 30, n. 4: pp. 663-686.

Carneiro, R. (2008) “Globalização e inconversibilidade monetária”, Revista de Economia Política, vol. 28, n. 4, pp. 539-556.

Carneiro, R. \& Rossi, P. (2012) The Brazilian experience in managing interest-exchange rate nexus, Texto para Discussão. IE/Unicamp, Campinas, n. 206, jun. 2012

De Grauwe, P. \& Grimalde, M. (2006) The exchange rate in a behavioral finance framework, Oxford: Princeton University Press.

Dodd, R. \& Griffith-Jones, S. (2007) Brazil's Derivatives Markets: Hedging, Central Bank Intervention and Regulation, Economic Commission for Latin America and the Caribbean (ECLAC).

Farhi, M. (1998) “O futuro no presente: um estudo sobre o mercado de derivativos financeiros". Tese de Doutorado, Campinas, IE/Unicamp.

Farhi, M. (2010) “Os impactos dos derivativos no Brasil”. in Marcolino, L.C., Carneiro, R. Sistema financeiro e desenvolvimento no Brasil, São Paulo: Atitude.

Franco, G. (2000) “The real plan and exchange rate”, Essays International Finance, Princeton University, n. 216.

Frankel, J. (2008) "Carried away: everything you always wanted to know about the carry trade, and perhaps much more”, Milken Institute Review, v. 10, n. 1, pp. 38-45.

Gagnon, J.E. \& Chaboud, A.P. (2007) "What can the data tell us about carry trades in Japanese yen?", International Finance Discussion Papers, No 899, Board of Governors of the Federal Reserve System.

Garcia, M. \& Urban, F. (2004) O Mercado Interbancário de Câmbio. Rio de Janeiro: Pontifícia Universidade Catolica do Rio de Janeiro.

He, D. \& McCauley, R. (2010) "Offshore markets for the domestic currency: monetary and financial stability issues”, BIS Working Papers, No. 320.

Hicks, J. (1974) The Crisis in Keynesian Economics. New York: Basic Books.

Keynes, J.M. (2000 [1924]) A Tract on Monetary Reform, Nova York: Prometheus Books. 
Klitgaard, T. \& Weir, L. (2004) "Exchange rate changes and net positions of speculators in the futures market", FRBNY Economic Policy Review, May.

Kohlher, M. (2010) “Exchange rates during financial crises”, BIS Quarterly Review, March 2010.

McCauley, R.N. \& McGuire, P. (2009) "Dollar appreciation in 2008: safe haven, carry trades, dollar shortage and overhedging”, BIS Quarterly Review, pp. 85-93, December.

Prates, D.M. (2009) "Os determinantes das taxas de câmbio nominal e real no Brasil no período 2003-2007”. in FERREIRA, F. \& MEIRELES, B. Ensaios Sobre Economia Financeira, Rio de Janeiro: BNDES.

Rossi, P. (2012) “Taxa de câmbio no Brasil: dinâmicas da arbitragem e da especulação”, Tese de Doutorado, Campinas, IE-Unicamp.

Sarno, L. \& Taylor, M.P. (2006) The Economics of Exchange Rates, Cambridge: Cambridge University Press.

Souza, F. E.P. \& Hoff, C.R. (2006) “O regime cambial brasileiro: sete anos de flutuação”, in Belinski, J. et al. (Orgs.). 15 Anos de Mercosur, Montevidéu: Editora Zonalibro.

Ventura, A. \& Garcia, M. (2009) "Mercados futuro e à vista de câmbio no Brasil: O rabo balança o cachorro," Texto para discussão 563, PUC-Rio.

Willianson, J. (2008) “Exchange rate economics”, Peterson Institute Working Paper Series, W P 08 - 3. 